\title{
Polymer-Modified Mortars for Surface Treatment with the Utilization of Waste Polystyrene
}

\author{
Nikol Žižkováa ${ }^{a}$ Rostislav Drochytka ${ }^{b}$ Karel Nosek ${ }^{c}$ \\ Brno University of Technology, Faculty of Civil Engineering, Department of Technology of Building \\ Materials and Components, Veveří 95, Brno, Czech Republic \\ azizkova.n@fce.vutbr.cz, ${ }^{b}$ drochytka.r@fce.vutbr.cz, ${ }^{\circ}$ nosek.k@fce.vutbr.cz
}

Keywords: Polymer-modified mortars, waste polystyrene.

\begin{abstract}
The article is focused on the observation of usable possibilities of waste polystyrene that is created during foundry production and that could be used for production of cellular construction material. Thanks to its granulometry this kind of waste polystyrene is very suitable for use in the fine-soft Polymer-Modified Mortars (PMM), for example in the paste and gluing materials determined for ETICS (External Thermal Insulation Composite Systems). The mixtures for waste polystyrene application feature the required cellular light property, they conform to the requirements on the solidity and adhesiveness and conform also to the tension tests for the reinforcing layer.
\end{abstract}

\section{Introduction}

According to Czech legislation, each person is bound to prevent waste production in his/her activity and to limit the volume and dangerous features of waste. If waste production cannot be prevented, the waste must be processed, eventually eliminated in a way, which does not endanger human health and the environment. This act obviously prefers processing the waste before elimination. An example is the so-called material use of waste, which also represents a substitution of raw materials extracted from waste, which can be considered as secondary raw materials. The actual producer should preferably use the produced waste, as in case these materials need to be transported; the transport costs markedly surpass the market price, for which the possible and usable waste can be bought from the producer. If the producer of usable waste is not able to process the produced waste effectively, he/she should offer the waste to another producer for use and, as far as the nonutilizable waste is concerned he/she must provide for its safe disposal.

Expanded polystyrene is currently used as a popular packing or insulating material in various industrial fields in the world. A large quantity of expanded polystyrene is consumed, and is disposed as a waste. Effective recycling countermeasures against the waste expanded polystyrene are strongly requested [1].

In the late 1950s and early 1960s, research into the use of polystyrene beads as replacement aggregate in concrete was carried out in West Germany. To overcome the hydrophobicity of polystyrene beads and the proneness to segregation in polystyrene concrete mixes, a bonding agent such a epoxy resin or aqueous dispersions of polyvinyl propionate to coat the polystyrene beads has been adopted successfully [2].

By incorporating the EPS beads at different volume percentages in the concrete, mortar, or cement paste, a wide range of concrete densities can be achieved. The EPS aggregate replaces wholly or partly the normal aggregate in the case of concrete, or sand in the case of mortars [3].

It was reported that expanded polystyrene can be used as ultra lightweight aggregate suitable for developing concretes for both structural and non-structural applications by varying its volume percentage in mortar or concrete. Moreover the use of high volume fly ash as a supplementary cementitious material in concrete applications is very much preferred for economy and durability apart from the advantages that are related to the environmental aspects [4]. 
EPS beads are extremely light with densities of only $12-20 \mathrm{~kg} \cdot \mathrm{m}^{-3}$ which can cause segregation in mixing. In addition, they are hydrophobic, which results in poor bonding to cement paste. Hence, some research have been done on: (1) adding some bonding additives such as aqueous epoxy emulsions and aqueous dispersions of polyvinyl propionate; (2) chemically treated EPS beads which are capable of preventing the segregation in the concrete mixes (commercially available as styrene-butadiene rubber aggregate in Australia); (3) adding ultra fine silica fume to improve the bonding between EPS and the cement paste. As a property-modified material for cement mortar, styrene-butadiene rubber (SBR) latex has widely been used for repair work of reinforced concrete structures. The research showed that adding SBR latex to the cement mortar could not only greatly improve bonding strength of the cement mortar but also its flexural and tensile strengths [5]. In study conducted by Chen and Liu [5], the addition of SBR latex to EPS concrete is tried to improve the bonding between EPS particles and cement paste and tensile and flexural strengths of EPS concrete.

\section{Polystyrene}

Expanded polystyrene (EPS). EPS is a light, solid and compact substance, which has been widely used in European civil engineering as heat and sound insulation. Thanks to its good impact strength combined with a very low weight, it is also an excellent packing material and has been used in other areas of human activity, e.g. the foundry industry.

About 3 million $\mathrm{m} 3$ of polystyrene is produced yearly in the Czech Republic, whereas $50 \%$ is EPS. The form of EPS is stable, it is not sensitive to moisture, it is resistant to decomposition as well as ageing, it is processed well and offers an excellent proportion between the price and utility value. Recycling of EPS in the Czech Republic is usually carried out in the form of processing it back into EPS products, civil engineering materials (polystyrene concrete, heat-insulation powder, insulating plasters etc.), and as it is an ecologically-sound material, it is also used in agriculture and gardening to improve heavy soils and as a lightening agent.

Production of EPS. Plastic materials on the polystyrene basis occupy with its production volume the third position in the world, following polyolefin and polyvinyl chloride. Polystyrene (PS) is made from styrene (vinyl benzene), which is liquid at ordinary temperatures and can be polymerized well in a unit or suspension. In the basic methylene chain, which forms a polystyrene molecule, a six-part aromatic circle (phenyl) is linked to every other carbon instead of hydrogen.

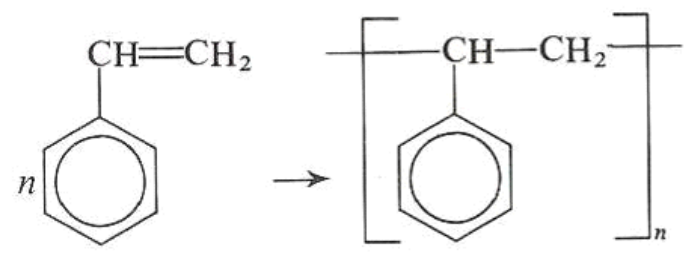

The incurred polymer is hard, but very brittle. The PS itself tends to create corrosion ruptures under pressure, namely when in contact with different kinds of surfactants, benzene, fat and alcohol. This limits its utilization possibilities. The fragility of PS is reduced through the copolymerisation of styrene with other caoutchouc monomer (butadiene), or mixing the PS with Indian rubber in a heated homogenizer mechanically. The double bonds in the Indian rubber make the aging resistance worse. This fact can be improved through stabilization just partially and the tough PS therefore cannot be recommended for external applications. Styrene copolymers with acrylonitrile and butadiene (ABS) and the acrylonitrile (SAN) itself have outstanding mechanical features for bearable costs. A considerable amount of styrene is consumed in civil engineering in the form of expanded PS. For building purposes, the expanded PS is produced with the help of either expansive or extrusive technology.

Expanded PS (EPS) is the most common expanded foam used currently in civil engineering. With regards to the C-value coefficient (which is about $0,04 \mathrm{~W} \cdot \mathrm{m}-1 . \mathrm{K}-1$ with the expanded PS), it is used mainly for heat-isolation products, however, some applications also use the low volume weight 
of EPS, with extraordinarily easy division of the EPS panels and easy carving of complicated shapes too.

The technologies of the expanded PS (EPS) production comes from the year 1949 and lie in the suspension polymerization of the styrene mixture and aliphatic hydrocarbon (most often pentane), through which the foamed up polystyrene granulation is produced. The granulation product consists of hard PS gems of about one millimeter, which absorb 5-7\% pentane. There are usually 3 phases in the processing of the foamed polystyrene to a lighter one. The pre-foaming, maturing and finishing the foaming in forms Slightly warm pentane (bp. $36^{\circ} \mathrm{C}$ ) is used as a foaming agent and the bead granulate material is pre-foamed at the temperature of about $100^{\circ} \mathrm{C}$, producing partially foamed beads with about a triple diameter. The volume of beads grows twenty to fifty times. The foamed beads are than left to mature and the expansion connected this time with the conglutination of expanding beads into one block is finished a few days later. The produced blocks are then cut into panels or even into more complicated parts.

Features of EPS. The main feature of EPS is its volume weight. The volume weight of the produced EPS can range from 5 to $100 \mathrm{~kg} \cdot \mathrm{m}^{-3}$, however, in the building practice the values of 20,25 and $35 \mathrm{~kg} \cdot \mathrm{m}^{-3}$ are used. The C-value coefficient of EPS can be estimated on the basis of the volume weight using a regressive relationship stated in ČSN EN 13 163. Technical features of EPS are shown in table 1.

Table 1: Technical features of EPS depending on the volume weight.

\begin{tabular}{|c|c|c|c|c|}
\hline Characteristics & Unit & \multicolumn{2}{|c|}{ Kind (according to the volume weight) } \\
\hline Volume weight & {$\left[\mathrm{kg} \cdot \mathrm{m}^{-3}\right]$} & 15 & 20 & 30 \\
\hline C-value coefficient & {$\left[\mathrm{W} \cdot \mathrm{m}^{-1} \mathrm{~K}^{-1}\right]$} & 0.039 & 0.037 & 0.035 \\
\hline Absorption power 7 days & Volume $[\%]$ & 3.00 & 2.30 & 2.0 \\
\hline Flexural strength & {$\left[\mathrm{N} \cdot \mathrm{mm}^{-2}\right]$} & 0.18 & 0.28 & 0.46 \\
\hline Compression strength & {$\left[\mathrm{N} \cdot \mathrm{mm}^{-2}\right]$} & 0.07 & 0.14 & 0.22 \\
\hline Vapor diffusion coefficient & - & \multicolumn{3}{|c|}{$0.0028 .10^{-9}$} \\
\hline Specific caloric receptivity & {$\left[\mathrm{J}^{-1} \mathrm{~kg}^{-1} \cdot \mathrm{K}^{-1}\right]$} & \multicolumn{3}{|c|}{$\mathrm{B} 0.10^{-6}-70.10^{-6}$} \\
\hline Temperature expandability coefficient & {$\left[\mathrm{K}^{-1}\right]$} & \multicolumn{3}{|c|}{} \\
\hline Combustibility DIN 4102 & \multicolumn{3}{|c|}{} \\
\hline
\end{tabular}

Using the waste EPS for the PMM production. When formatting the EPS through cutting, part of the EPS falls away in the form of beads, detached from the original piece. Individual expanded beads can also be obtained through crushing the EPS. The cutting residue or intentionally crushed EPS is used in civil engineering as a powder or filling in polystyrene concrete and insulating coatings. The heat insulating core coating on the basis of EPS shows a C-value coefficient of only $0,075 \mathrm{~W} \cdot \mathrm{m}^{-1} \mathrm{~K}^{-1}$, which is only $70 \%$ of the C-value of regular heat insulating pearlite coatings. Although the polystyrene mechanical features are low, the light polystyrene concrete prefabricated elements are interesting with their thermal resistance as well as their exceptionally easy flexibility.

Based on excellent results during the waste polystyrene application into the polystyrene concrete and heat insulating coatings, a check of its suitability for the PMM production was carried out.

Namely screeding and adhesive materials for ETICS, with the following goals being set:

- To use waste polystyrene for the screeding and adhesive materials production for ETICS (with the maximum volume weight of $1500 \mathrm{~kg} \cdot \mathrm{m}^{-3}$ ).

- To check the possibility of dispergator use to simplify the preparation of screeding and adhesive materials containing waste polystyrene as a filling component.

- To check the possibility of a simultaneous application of the waste polystyrene and fly ash in the monitored values. 


\section{Selected results}

Used waste EPS and fly ash. The waste EPS (volume weight of $18.3 \mathrm{~kg} \cdot \mathrm{m}^{-3}$ ) was used in the process, which is produced during the manufacture of forms for product casting in the foundry and machine plant, where the polystyrene is cut and ground into the required shape. Waste, produced during the cutting and grinding is sucked off into sacks and stored. Furthermore, the fly ash from a power station incinerating brown coal, the dominant parts of which are $\mathrm{SiO}_{2}(52.4 \%)$ and $\mathrm{Al}_{2} \mathrm{O}_{3}$ $(24.2 \%)$ was used.

The effect of waste EPS on the final features. The structure of suggested mixtures (referential and the waste EPS mixtures) is shown in table 2. Detected results are shown in table 3 and in figures 1 and 2 .

Table 2: Composition of reference mixtures for ETICS.

\begin{tabular}{|l|l|c|c|c|c|c|}
\hline \multicolumn{2}{|c|}{ Component of mixture for ETICS } & \multicolumn{5}{c|}{ Composition of mixtures [\%] } \\
\cline { 3 - 6 } \multicolumn{2}{|l}{} & $\mathrm{A} / 0$ & $\mathrm{~B} / 0,5$ & $\mathrm{C} / 1$ & $\mathrm{D} / \mathrm{FA} 1$ & E/FA2 \\
\hline Binder & Cement CEM I 52.5 R & 38.00 & 38.00 & 38.00 & 38.00 & 38.00 \\
\hline Filler & Siliceous sand & 16.60 & 16.60 & 16.60 & 0.00 & 43.262 \\
\hline & Ground limestone 0.2 - 0.5 mm & 40.40 & 37.55 & 34.70 & 43.262 & 0.00 \\
\hline & Waste polystyrene & 0.00 & 2.85 & 5.70 & 4.04 & 4.04 \\
\hline & Fly ash & 0.00 & 0.00 & 0.00 & 9.696 & 9.696 \\
\hline $\begin{array}{l}\text { Additi } \\
\text { ves }\end{array}$ & $\begin{array}{l}\text { Copolymer EVA, foam remover, } \\
\text { cellulose ether }\end{array}$ & 5.0 & 5.0 & 5.0 & 5.0 & 5.0 \\
\hline
\end{tabular}

Table 3: Properties of mixtures with waste polystyrene.

\begin{tabular}{|c|c|c|c|c|c|}
\hline Sample mark & $\mathrm{A} / 0$ & $\mathrm{~B} / 0,5$ & $\mathrm{C} / 1$ & $\mathrm{D} / \mathrm{FA} 1$ & $\mathrm{E} / \mathrm{FA} 2$ \\
\hline $\begin{array}{c}\text { Density } \\
{\left[\mathrm{kg} \cdot \mathrm{m}^{-3}\right]}\end{array}$ & 1610 & 1380 & 1250 & 1320 & 1420 \\
\hline
\end{tabular}

Tension and Bending Strength

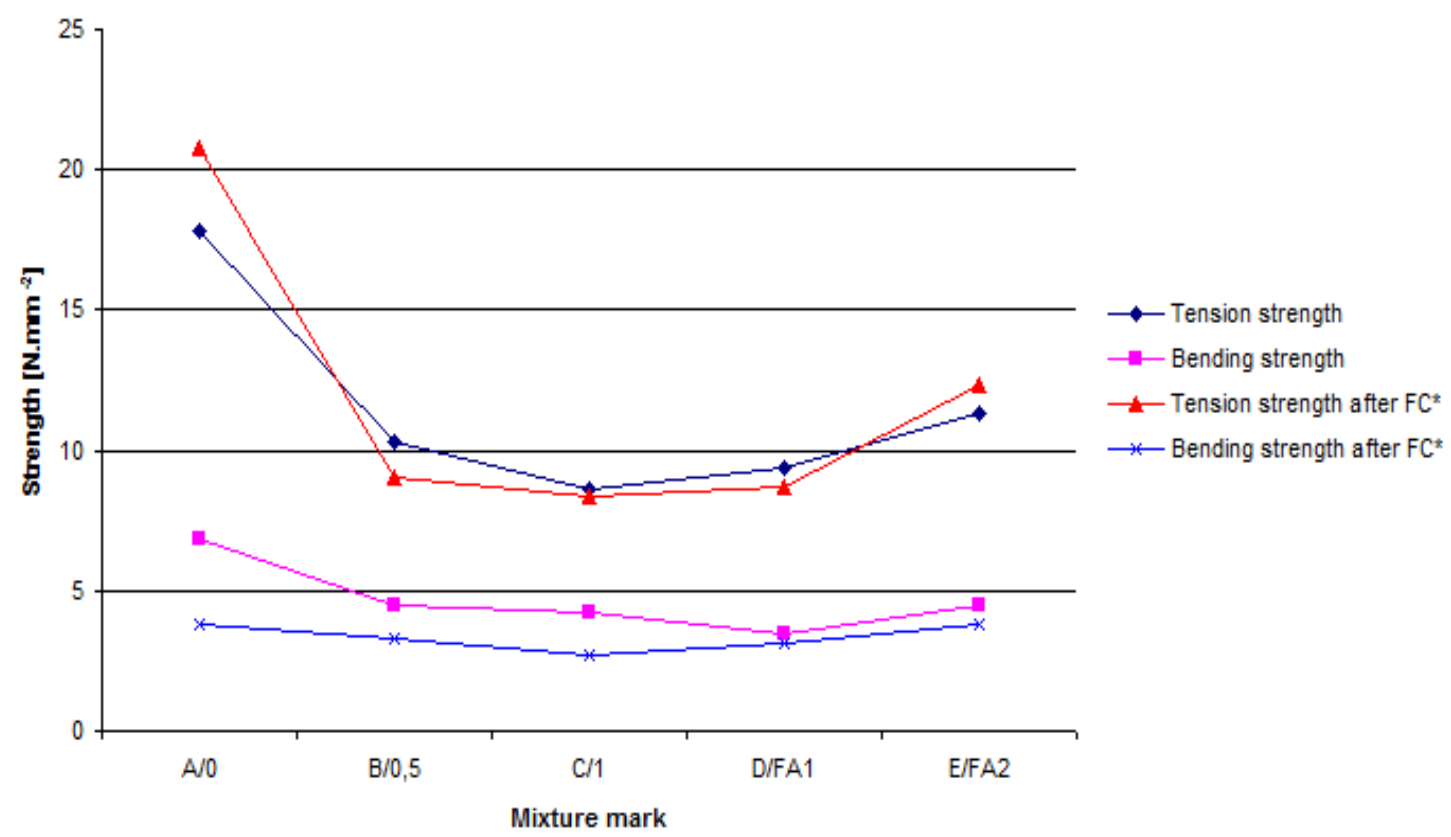

[Note]*FC - 25 freezing cycles

Figure 1: Determination of strength according to ČSN EN 12808-3 mixtures with waste 
polystyrene.

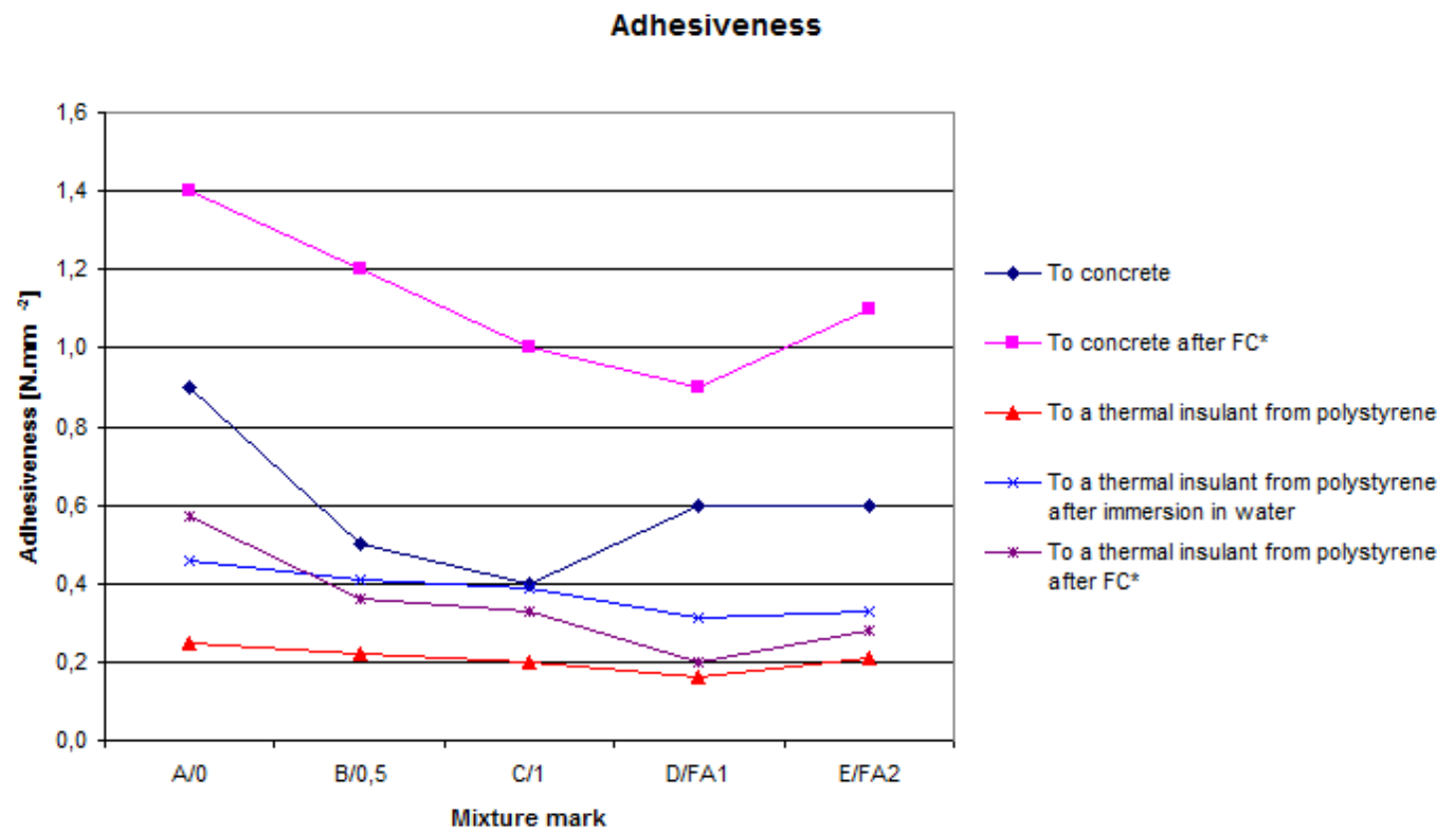

[Note]*FC - 25 freezing cycles

Figure 2: Determination of adhesiveness according to ČSN EN 1542 mixtures with waste polystyrene.

According to expectations, the volume weight was reduced and the related pull and push pressure was reduced, however, very positive results were found in the rest. E/FA2 was selected as the most suitable mixture, showing the required lightening and fulfilling the set parameters, hence additional tests were carried out and the mixture was compared with the reference mixture, i.e. the mixture without waste polystyrene, see table 4 and 5 .

Table 4: Results of additional tests.

\begin{tabular}{|c|c|c|c|c|}
\hline \multirow{2}{*}{ Sample } & C-value coefficient & \multicolumn{3}{|c|}{ Dynamic flexibility module } \\
\cline { 3 - 5 } & & \multicolumn{3}{|c|}{$\mathrm{GPa}$} \\
\hline Mark & {$\left[\mathrm{W}^{-1} \mathrm{~m}^{-1} \cdot \mathrm{K}^{-1}\right]$} & After 1 day & After 7 days & After 14 days \\
\hline A/0 & 0.574 & 5.8 & 12.1 & 10.6 \\
\hline E/AF2 & 0.345 & 5.2 & 12.2 & 10.6 \\
\hline
\end{tabular}

Table 5: Results of porosity determining.

\begin{tabular}{|c|c|c|c|c|}
\hline Sample & Total pore volume & Total pore area & Specific weight & Total porosity \\
\hline Mark & {$\left[\mathrm{mm}^{3} \cdot \mathrm{g}^{-1}\right]$} & {$\left[\mathrm{m}^{2} \cdot \mathrm{g}^{-1}\right]$} & {$\left[\mathrm{g} \cdot \mathrm{cm}^{-3}\right]$} & $\%$ \\
\hline A/0 & 225.5648 & 17.461 & 2.2791 & 33.9535 \\
\hline E/AF2 & 263.1792 & 17.790 & 2.2357 & 37.0433 \\
\hline
\end{tabular}




\section{RDA record}

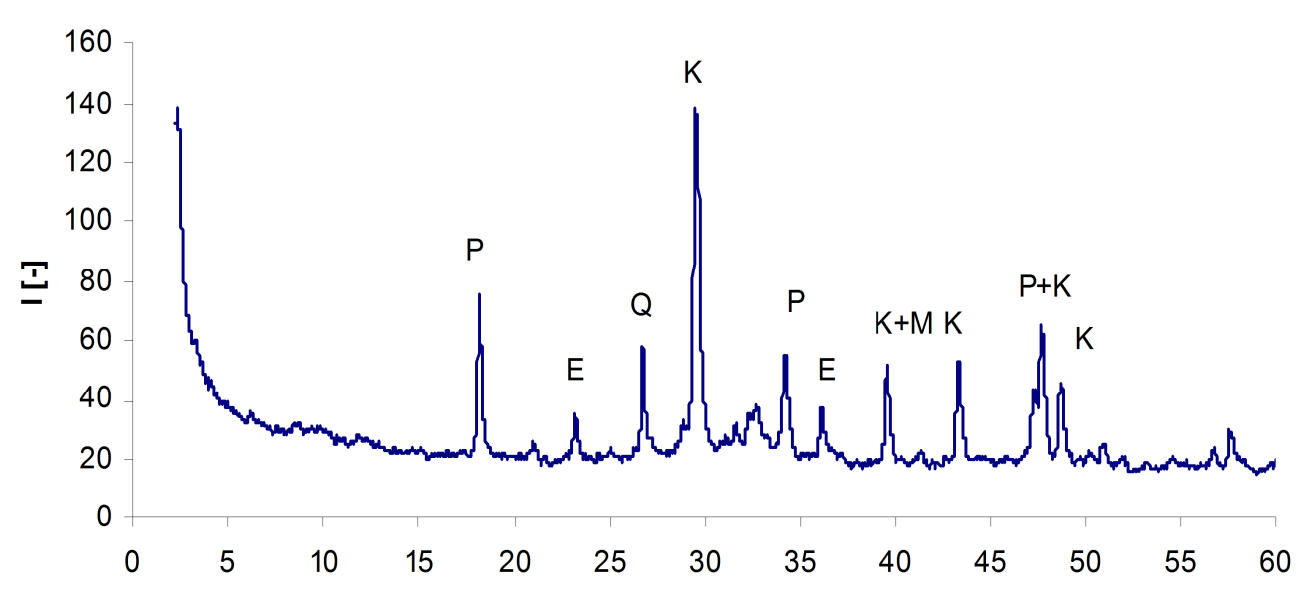

Calcite (K), Portlandite (P), Ettringite (E), Quartz (Q), Mullite (M) Figure 3: RDA record of the E/AF2 mixture.

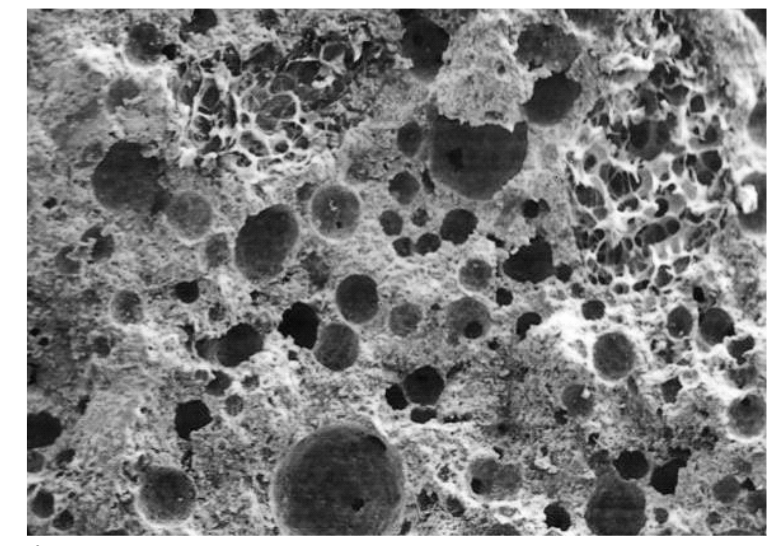

a)

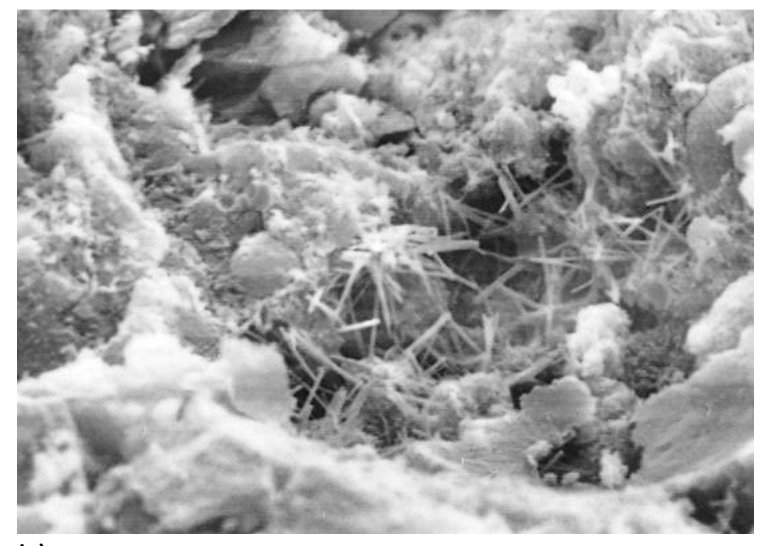

b)

Figure 4: Photos from REM of E/FA2 mixture containing waste polystyrene and fly ash as filling component, a) magnification of 50 times and b) magnification 3000 times.

Figure 3 shows an RDA record of the mixture containing waste polystyrene and fly ash, which does not show any abnormalities. Figure 4 shows a pored structure and visible polystyrene parts (in circles), the next picture shows a detail in a pore with the rests of the ettringite needles. Additional tests confirmed the E/FA2 mixture suitability as well; therefore this mixture was further modified using three types of dispersant additives. This issue was included on the basis of a practice-based requirement, assuming the production of this mixture as dry screeding and adhesive materials (packed in $25 \mathrm{~kg}$ sacks), which will be prepared by mixing with water at the construction site. To make the assortment of the polystyrene parts easier and to ensure the mixture homogeneity, were added special mixtures containing condensation polymer of the sulphone melamine with formaldehyde, hexametaphosphate and polycarboxylate. The E/FA2 mix composition containing dispersant agents are shown in table 6. 
Table 6: The E/FA2 mix composition containing dispersant agents.

\begin{tabular}{|c|c|}
\hline Sample mark & Dispersant agent addition to the E/FA2 mixture \\
\hline$E / 1 / 0.45$ & $0.45 \%$ condensation polymer of the sulphone melamine with formaldehyde \\
\hline$E / 1 / 0.9$ & $0.9 \%$ condensation polymer of the sulphone melamine with formaldehyde \\
\hline$E / 1 / 1.35$ & $1.35 \%$ condensation polymer of the sulphone melamine with formaldehyde \\
\hline$E / 2 / 0.01$ & $0.01 \%$ hexametaphosphate \\
\hline$E / 2 / 0.02$ & $0.02 \%$ hexametaphosphate \\
\hline$E / 2 / 0.03$ & $0.03 \%$ hexametaphosphate \\
\hline$E / 3 / 0.2$ & $0.2 \%$ polycarboxylate \\
\hline$E / 3 / 0.35$ & $0.35 \%$ polycarboxylate \\
\hline$E / 3 / 0.5$ & $0.5 \%$ polycarboxylate \\
\hline
\end{tabular}

Firmness and holding ability were monitored. Detected results are shown in table 7 and in figures 5 and 6.

Table 7: Characteristics of features containing dispersant agents.

\begin{tabular}{|c|c|c|c|c|c|c|c|c|c|}
\hline $\begin{array}{c}\text { Sample } \\
\text { mark }\end{array}$ & $\mathrm{E} / 1 / 0.45$ & $\mathrm{E} / 1 / 0.9$ & $\mathrm{E} / 1 / 1.35$ & $\mathrm{E} / 2 / 0.01$ & $\mathrm{E} / 2 / 0.02$ & $\mathrm{E} / 2 / 0.03$ & $\mathrm{E} / 3 / 0.2$ & $\mathrm{E} / 3 / 0.35$ & $\mathrm{E} / 3 / 0.5$ \\
\hline $\begin{array}{c}\text { Density } \\
{\left[\mathrm{kg} . \mathrm{m}^{-3}\right]}\end{array}$ & 1460 & 1580 & 1470 & 1400 & 1410 & 1310 & 1450 & 1480 & 1520 \\
\hline
\end{tabular}

Tension and Bending Strength

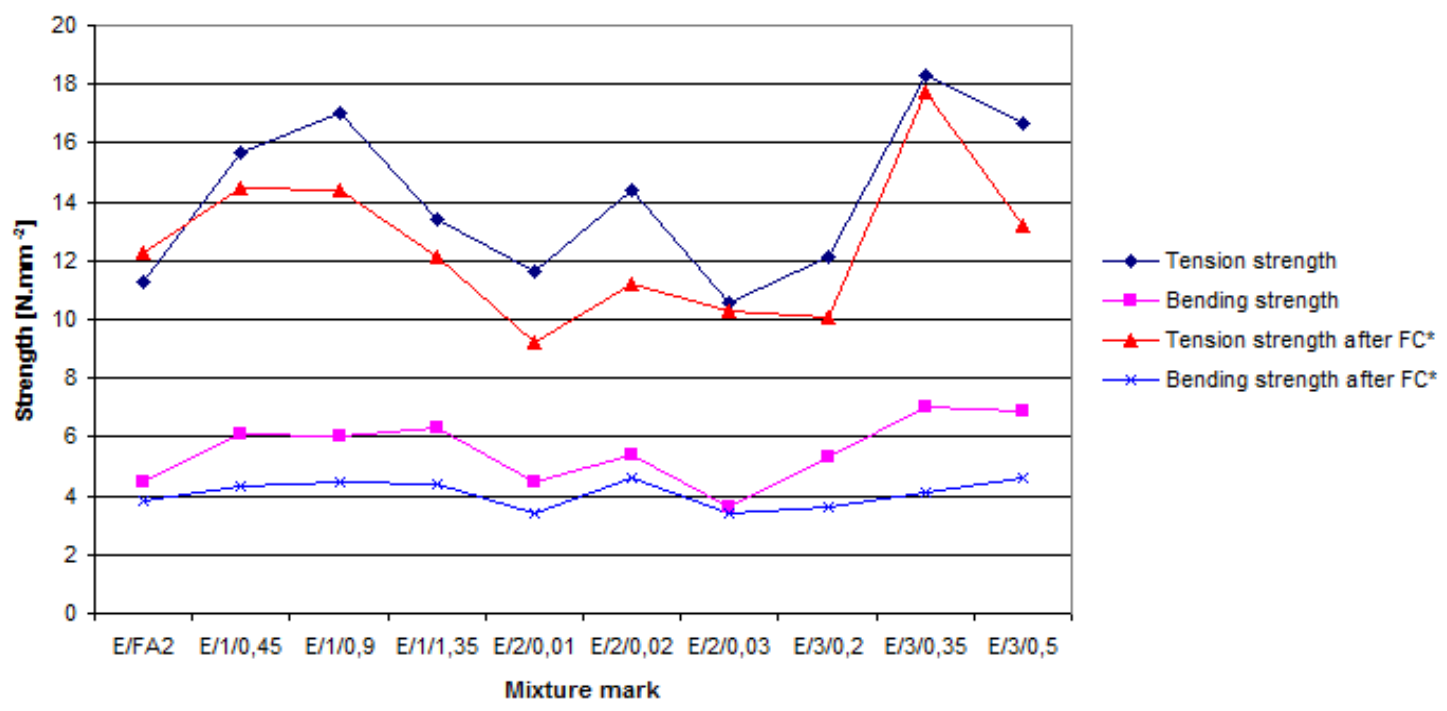

[Note]* FC - 25 freezing cycles

Figure 5: Determination of strength according to ČSN EN 12808-3 mixtures with waste polystyrene, fly ash and dispersant agents. 


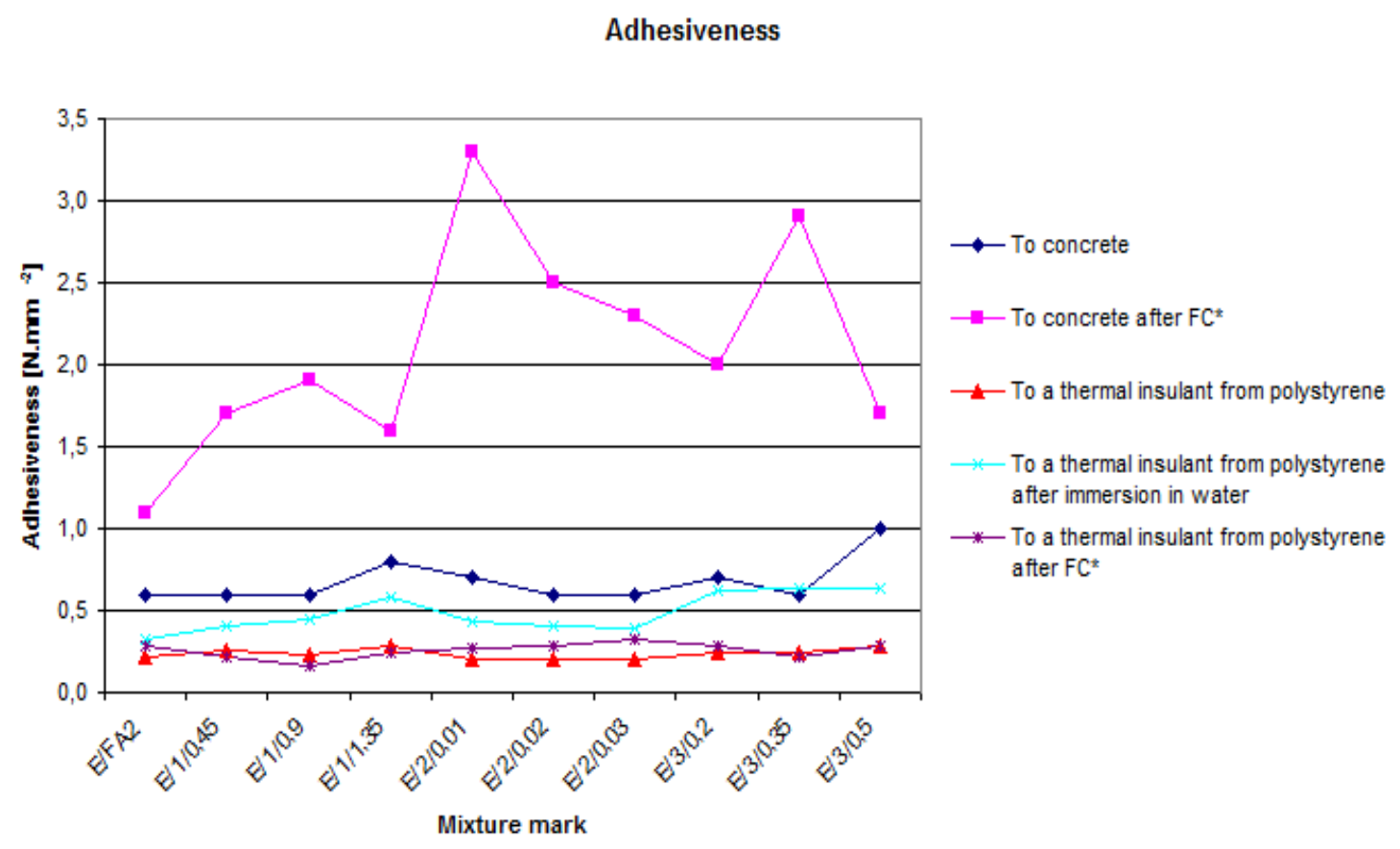

[Note]*FC - 25 freezing cycles

Figure 6: Determination of adhesiveness according to ČSN EN 1542 mixtures with waste polystyrene, fly ash and dispersant agents. 
Tension test of base (reinforcing) layer for ETICS. Reinforcing layer is to be made directly on the outer surface of thermal insulation. It should be done by using a method of the reinforcing meshwork's whole-surface pushing to a previously applied layer of gravel and by consequent floatation so that the meshwork gets surrounded by gravel mass on both sides. The reinforcement procedure must be done within the entire area of thermal insulation, it must be strengthened in places where stressing strength is higher. The reinforcement improves the mechanical characteristics of the ETICS outer layers. Usually, they consist of glass fibre net (fibre-glass fabric made of consecutive yarn) with a mesh size of at least $3 \mathrm{~mm}$ which is protected on its surface. Among the most popular surface treatments of glass, there are materials based on styrene-butadiene which are used to increase mechanical resistance and especially to ensure the desired alkaline resistance. Because of the fact that the quality of reinforcing layer has significant impact on mechanical characteristics, stability and durability of the ETICS, it was also necessary to perform a tension test. There was also a monitoring procedure for cracks done by the method of elongation by $1.5 \%$ (maximum width of crack is $0.15 \mathrm{~mm}$ according to Rules of Czech ETICS Association). The tests which were carried out confirmed the reduction in the number and width of cracks regarding the mixture of E/FA2 compared with reference mixtures (see figures $7 \mathrm{a}, \mathrm{b}, \mathrm{c}$ ).

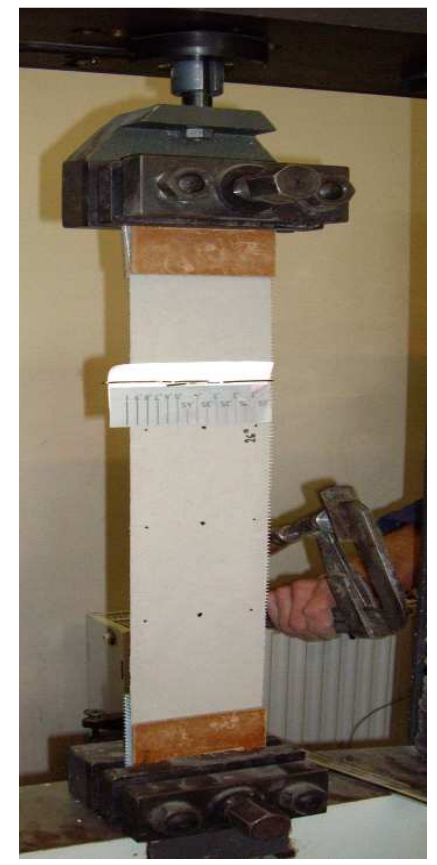

a)

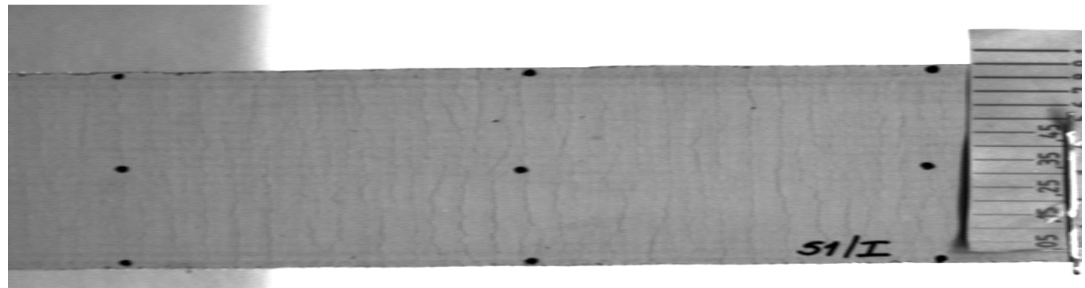

b)

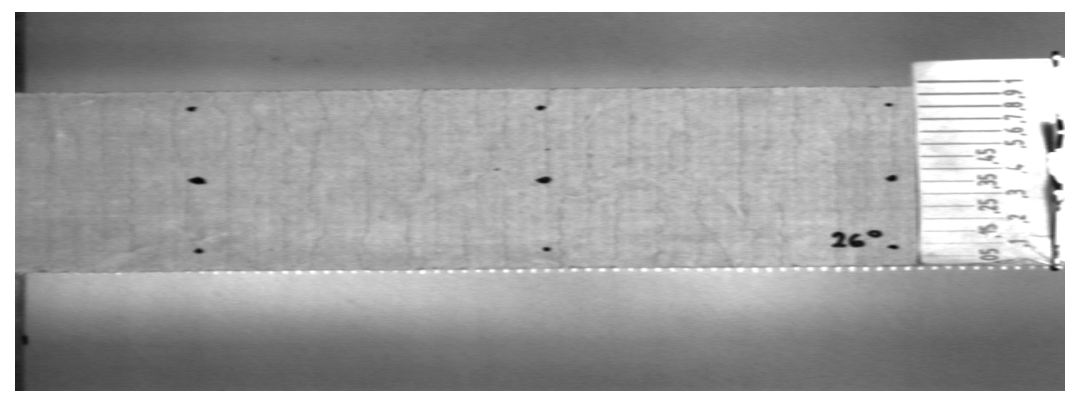

c)

Figure 7: a) testing of base layer (including glass meshwork), b) mixture without fly ash and waste EPS (Max. width of cracks: $0,15 \mathrm{~mm}$ ), c) mixture containing $25 \%$ of fly ash and $1 \%$ of waste EPS as filling component (Max. width of cracks: 0,10 mm)

\section{Discussion}

According to expectations, the volume weight was reduced and the related compressive and bending strength was reduced, but in case of adhesiveness were observed very positive results. E/FA2 was selected as the most suitable mixture, showing the required lightening and fulfilling the set parameters. Most of the studies reported to date were essentially on concretes of lower densities (below $1300 \mathrm{~kg} \cdot \mathrm{m}^{-3}$ ) resulting in strengths below $12 \mathrm{MPa}$ (Ganesh Babu and Saradhi Babu, 2002). In our study, we obtained compressive strengths of 8,6 - 11,3 $\mathrm{MPa}$ (density $1250-1420 \mathrm{~kg} \cdot \mathrm{m}^{-3}$ ) and after modification with dispersants compressive strengths were improved up to 9,6 - 18,3 MPa (density 1310 - $1580 \mathrm{~kg} \cdot \mathrm{m}^{-3}$ ), which is very significant improvement.

All the EPS mixtures showed better flow and no segregation was observed in any mix even these 
concretes made without the addition of bonding additives [4]. Other investigators also reported that EPS tends to float and can result in a poor mix distribution and segregation, necessitating the use of admixtures [3]. In case of screeding and adhesive materials for ETICS was necessary to use dispersant additives. Conducted laboratory tests confirmed that all three dispersants made mixing and the following homogenisation of the mixture easier. As evident from figures 5 and 6 , a significant growth of solidity as well as holding ability was achieved in some cases. This fact becomes evident with mixtures containing hexametaphosphate and polycarboxylate at higher levels. In case of the holding ability to the concrete after freezing cycles, a growth of the holding ability compared with the results found with mixture without dispersant additives was determined.

\section{Acknowledgements}

This work was published with the financial support of the research project: MSM 0021630511 „Progressive Building Materials with Utilization of Secondary Raw Materials and their Impact on Structures Durability“.

\section{References}

[1] N. W.Choi, Y. Ohama: Development and testing of polystyrene mortars using waste EPS solution-based binders, Construction and Building Materials 18, (2004), p. 235-241.

[2] W.C. Tang, Y.Lo, A. Nadeem: Mechanical an drying shrinkage properties of structural-graded polystyrene aggregate concrete, Cement \& Concrete Composites 30, (2008), p.403-409.

[3] K. Ganesh Babu, D. Saradhi Babu: Behavior of lightweight expanded polystyrene concrete containing silica fume, Cement and Concrete Research 33, (2002), p. 755-762.

[4] D. Saradhi Babu, K. Ganesh Babu, T.H. Wee: Properties of lightweight expanded polystyrene aggregate concretes containing fly ash, Cement and Concrete Research 35, (2005), p. 12181223.

[5] B. Chen, J. Liu: Mechanical properties of polymer-modified concretes containing expanded polystyrene beads, Construction and Building Materials 21, (2007), p. 7-11. 